\section{Case Reports in Ophthalmology}

Case Rep Ophthalmol 2020;11:395-401

DOI: 10.1159/00050926

Published online: August 5, 2020
(C) 2020 The Author(s)

Published by S. Karger AG, Basel www.karger.com/cop

This article is licensed under the Creative Commons Attribution-NonCommercial 4.0 International License (CC BY-NC) (http://www.karger.com/Services/OpenAccessLicense). Usage and distribution for commercial purposes requires written permission.

\title{
Enlarged Foveal Avascular Zone after Whiplash Injury-Acquired Berlin's Edema
}

\author{
Nataša Drača ${ }^{a}$ Branimir Cerovski ${ }^{b}$ Ratimir Lazića Damir Kovačevićc \\ Krešimir Gabrića Ivan Gabrića \\ ${ }^{a}$ Department of Retina, University Eye Hospital Svjetlost, Zagreb, Croatia; ${ }^{b}$ Department of \\ Ophthalmology, University Hospital Centre Zagreb, Zagreb, Croatia; 'Department of \\ Ophthalmology, Clinical Hospital Centre Rijeka, Rijeka, Croatia
}

\section{Keywords}

Foveal avascular zone - Optical coherence tomography angiography · Berlin's edema ·

Whiplash injury

\section{Abstract}

We describe a case of optical coherence tomography angiography (OCTA) changes in the foveal avascular zone (FAZ) in a patient that had suffered Berlin's edema after a whiplash neck injury. The patient reported central scotoma throughout the 1-year follow-up, confirmed by visual field examination. OCTA showed FAZ enlargement of the left eye as compared to the healthy right eye in the superficial capillary layer and even more in the deep capillary layer. To the best of our knowledge, FAZ enlargement has not been previously described by OCTA after whiplash-related macular injury.

(C) 2020 The Author(s)

Published by S. Karger AG, Basel

\section{Introduction}

Berlin's edema, often related to blunt ocular trauma, is a rare finding after a whiplash injury with only a few cases described $[1,2]$. Patients usually present with severe visual loss or scotomas. However, in some patients, clinical findings could be very subtle and you can only 
find specific changes on optical coherence tomography (OCT), which has, to this date, been a golden standard examination allowing visualization of the macular structural abnormalities [3]. On the contrary, retinal vascular changes in optical coherence tomography angiography (OCTA) reports have not yet been confirmed in commotio retinae [4]. We describe a case of OCTA changes in the foveal avascular zone (FAZ) of a patient that had suffered Berlin's edema after whiplash injury.

\section{Case Report}

A 48-year-old male obtained a whiplash neck injury and a fracture of the articulate processes of the 7th neck vertebrae from a traffic accident. Two days later, he reported blurred vision in the left eye (LE). Although the best corrected visual acuity (BCVA) was 20/25, Amsler grid test was positive. There was preretinal paramacular hemorrhage on fundus examination. OCT, OCTA, visual field (VF) examination, fluorescein angiography (FA), and multifocal electroretinogram (mfERG) were performed. To analyze foveal structure and thickness, we utilized a swept-source (SS)-OCT and OCTA system (Triton, Topcon, Tokyo, Japan). The central retinal thickness (CRT) was defined as the average thickness in the central circle area. For OCTA, $4.5 \times 4.5 \times 4.5 \mathrm{~mm}^{3}$ macular cubes were obtained. En face images of the retinal vasculature were created from the superficial capillary layer (SCL) and deep capillary layer (DCL), based on the automated layer segmentation. The FAZ area was defined as the area inside the central border of the capillary network and was manually delineated on the inner border using the standard software and then calculated automatically. VF was measured in macular program (M program, Octopus 900, Haag-Streit, USA) and mfERG and FA (Canon) were performed accordingly. OCT showed no fluid but a slight disruption of the outer plexiform layer (OPL), outer nuclear layer (ONL), retinal pigment epithelial (RPE) layer, and photoreceptors (PR) with hyper-reflectivity of the ellipsoid zone (EZ) and interdigitation zone (IZ) and remained unchanged throughout the 1-year follow-up (Fig. 1). CRT was 241 and $257 \mu \mathrm{m}$ for the LE and RE, respectively. VF showed fixed central scotoma (Fig. 2). mfERG was unremarkable. FA revealed late paramacular hyperfluorescence in both eyes. OCTA showed an enlarged FAZ area in the SCL of $334,402 \mu \mathrm{m}^{2}$ in the LE as compared to $253,521 \mu \mathrm{m}^{2}$ in the RE, as well as in the DCL, measuring $814,944 \mu \mathrm{m}^{2}$ in the LE as compared to $311,858 \mu \mathrm{m}^{2}$ in the RE, respectively (Fig. 3).

\section{Discussion/Conclusion}

Berlin's edema was acquired after the whiplash injury and not after the blunt trauma. However, the mechanism of injury is presumed to be the same: rapid deceleration of ocular tissues. Chronopoulos et al. [1] described a case report of bilateral macular edema that resolved 7 days after the whiplash accident with no anatomical or functional changes 1 year after the accident. In our patient, BCVA was 20/25 but with central scotoma which persisted throughout the 1-year follow-up. Yet, the mfERG was normal for both eyes despite the fixed central scotoma confirmed by VF. Since the mfERG was done a few months after the accident, we could not compare or be certain that there were no changes initially. The fundus examination had shown preretinal hemorrhage and retinal opacification, which resolved after 2 weeks, and with the macular finding later being insignificant. OCT revealed changes in OPL and ONL, the hyper-reflectivity of the inner segment/outer segment (IS/OS) junction in the 


\section{Case Reports in Ophthalmology}

Case Rep Ophthalmol 2020;11:395-401

DOI: $10.1159 / 000509264$

C 2020 The Author(s). Published by S. Karger AG, Basel www.karger.com/cop

Drača et al.: Enlarged Foveal Avascular Zone after Whiplash Injury-Acquired Berlin's Edema

EZ, and disruption of the outer segment in the PR, IZ, and RPE from the first day to the 1-year follow-up. Histopathological studies in Berlin's edema have in fact shown that it is primarily characterized by damage of PR outer segments, IS/OS, and RPE [5]. The breakdown of the blood-retinal barrier due to trauma is one possible factor [6]. Since EZ is formed mainly by mitochondria of the outer portion of the inner segments of the PR and IZ corresponds to the contact of the RPE cells apices with the part of the cone outer segment, it is reasonable to believe that observed EZ and IZ integrity changes are also an important predictor of VA. In fact, in other retinal diseases, such as dry and wet age-related macular degeneration, diabetic macular edema, and after surgeries for epiretinal membrane, retinal detachment, and macular hole, VA correlated with the changes of EZ and IZ on OCT [7]. In our patient, despite rather good VA, the damaged PR in EZ and IZ were probably the cause of central scotoma and metamorphopsia.

OCTA showed enlargement of the FAZ in the LE. The FAZ, as a capillary-free area in the central macula, is in proximity to the highest cone photoreceptor density and oxygen consumption [8]. Enlargement has not yet been described in Berlin's edema macular injury. In healthy eyes, the size of the FAZ is not expected to affect visual function, but in retinal diseases it could be codependent [9]. In fact, SS-OCTA in diabetic retinopathy patients can be used to quantitatively demonstrate alterations in the FAZ and SCL/DCL compared to normal eyes [10]. Also, a larger FAZ has been reported in eyes with branch retinal vein occlusion (BRVO) after resolution of cystoid macular edema [11]. It is hypothesized that the inner retina damage is responsible for the enlargement of FAZ. Yu et al. [12] showed that the inner retina was relatively anoxic following experimental retinal arterial occlusion, providing evidence that vasculogenic insults to the fovea influence oxygen supply and consumption within the inner retina. Because the choroid is unable to sufficiently oxygenate the inner retina following retinal vascular injury, it is plausible that FAZ size would correlate with the degree of visual dysfunction in diabetic retinopathy and BRVO [12]. A similar mechanism could occur after the traumatic injury. Furthermore, the OPL and ONL deviations we observed on OCT could additionally confirm a postinjury ischemic event. The PR axon terminals filled with mitochondria are located in the OPL and may be more reliant on the blood supply of the DCL. However, the PR inner and outer segments receive $90 \%$ of their blood supply from the choriocapillaris. This makes the OPL and ONL the ridge zone between 2 sources of blood supply and rather vulnerable for ischemic events [13].

Since for the inner retina, the vascular supply comes from the inner retinal circulation, the existence of the FAZ could also be related to the thickness of the inner retinal tissue. Chui et al. [14] have found that the inner retinal thickness measured at the margin of the FAZ remains constant with increasing FAZ effective diameter in healthy eyes. Fujiwara et al. [15] reported that CRT and retinal vascular density were negatively correlated with FAZ in a healthy population. In our patient, there was no significant difference in CRT between the eyes, although in the LE it was thinner.

The enlarged FAZ could be a direct consequence of retinal injury with a similar mechanism of ischemia as described in BRVO and diabetic macular edema. Moreover, detected changes of localized hyper-reflectivity of the OPL and ONL layer, EZ, and IZ on OCT could be a direct consequence of the vasculogenic effect of the trauma on PR reflecting as FAZ enlargement on OCTA. In case of subtle changes on OCT and FA, OCTA needs to be done and in some cases could confirm a more serious disturbance of visual function. OCTA and FAZ changes need further research in posttraumatic maculopathies since they could correlate better with visual rehabilitation and prognosis, especially if detected early enough. 


\section{Case Reports in Ophthalmology}

\section{Statement of Ethics}

Data and images collected in this case report were approved by the patient by using a consent form and by the Ethical Committee of University Eye Hospital Svjetlost to be treated with confidentiality if published and in accordance with the Declaration of Helsinki.

\section{Conflict of Interest Statement}

The authors do not have any financial or proprietary interests in the materials described in the article.

\section{Funding Sources}

The authors have not received any grant support or research funding.

\section{Author Contributions}

Nataša Drača is the first and corresponding author contributing to the conception and design as well as writing the article and collecting and interpreting the data. Branimir Cerovski is acknowledged for conception of the article, collecting data, and critical revision of the manuscript. Ratimir Lazić contributed to the conception and critical revision, and Damir Kovačević contributed to the critical revision of the manuscript. Krešimir Gabrić and Ivan Gabrić contributed to data collecting.

\section{References}

1 Chronopoulos A, Lipski A, Jonescu-Cuypers CP, Thumann G. Unusual bilateral traumatic maculopathy following whiplash injury. BMJ Case Rep. 2014 Nov;2014:bcr2014208068.

2 McCannel CA. OCT III imaging of whiplash maculopathy. Eye (Lond). 2011 Apr;25(4):531-2.

3 Ahn SJ, Woo SJ, Kim KE, Jo DH, Ahn J, Park KH. Optical coherence tomography morphologic grading of macular commotio retinae and its association with anatomic and visual outcomes. Am J Ophthalmol. 2013 Nov;156(5):994-1001.e1.

4 Mansour AM, Shields CL. Microvascular Capillary Plexus Findings of Commotio Retinae on Optical Coherence Tomography Angiography. Case Rep Ophthalmol. 2018 Nov;9(3):473-8.

5 Blight R, Hart JC. Histological changes in the internal retinal layers produced by concussive injuries to the globe. An experimental study. Trans Ophthalmol Soc U K. 1978;98(2):270-7.

6 Moon K, Kim KS, Kim YC. A case of expansion of traumatic choroidal rupture with delayed-developed outer retinal changes. Case Rep Ophthalmol. 2013 Aug;4(2):70-5.

7 Turgut B, Demir T. The new landmarks, findings and signs in optical coherence tomography. New Front Ophthalmol. 2016;2(3):131-6.

8 Jonas JB, Schneider U, Naumann GO. Count and density of human retinal photoreceptors. Graefes Arch Clin Exp Ophthalmol. 1992;230(6):505-10.

9 Samara WA, Say EA, Khoo CT, Higgins TP, Magrath G, Ferenczy S, et al. Correlation of foveal avascular zone size with foveal morphology in normal eyes using optical coherence tomography angiography. Retina. 2015 Nov;35(11):2188-95.

10 Al-Sheikh M, Akil H, Pfau M, Sadda SR. Swept-source OCT angiography imaging of the foveal avascular zone and macular capillary network density in diabetic retinopathy. Invest Ophthalmol Vis Sci. 2016 Jul;57(8):3907-13. 


\section{Case Reports in Ophthalmology}

\begin{tabular}{l|l}
\hline DOI: $10.1159 / 000509264$ & (c) 2020 The Author(s). Published by S. Karger AG, Basel
\end{tabular}
www.karger.com/cop

Drača et al.: Enlarged Foveal Avascular Zone after Whiplash Injury-Acquired Berlin's Edema

11 Brar M, Sharma M, Grewal SP, Grewal DS. Quantification of retinal microvasculature and neurodegeneration changes in branch retinal vein occlusion after resolution of cystoid macular edema on optical coherence tomography angiography. Indian J Ophthalmol. 2019 Nov;67(11):1864-9.

12 Yu DY, Cringle SJ, Yu PK, Su EN. Intraretinal oxygen distribution and consumption during retinal artery occlusion and graded hyperoxic ventilation in the rat. Invest Ophthalmol Vis Sci. 2007 May;48(5):2290-6.

13 Rahimy E, Sarraf D. Paracentral acute middle maculopathy spectral-domain optical coherence tomography feature of deep capillary ischemia. Curr Opin Ophthalmol. 2014 May;25(3):207-12.

14 Chui TY, VanNasdale DA, Elsner AE, Burns SA. The association between the foveal avascular zone and retinal thickness. Invest Ophthalmol Vis Sci. 2014 Sep;55(10):6870-7.

15 Fujiwara A, Morizane Y, Hosokawa M, Kimura S, Shiode Y, Hirano M, et al. Factors affecting foveal avascular zone in healthy eyes: an examination using swept-source optical coherence tomography angiography. PLoS One. 2017 Nov;12(11):e0188572.

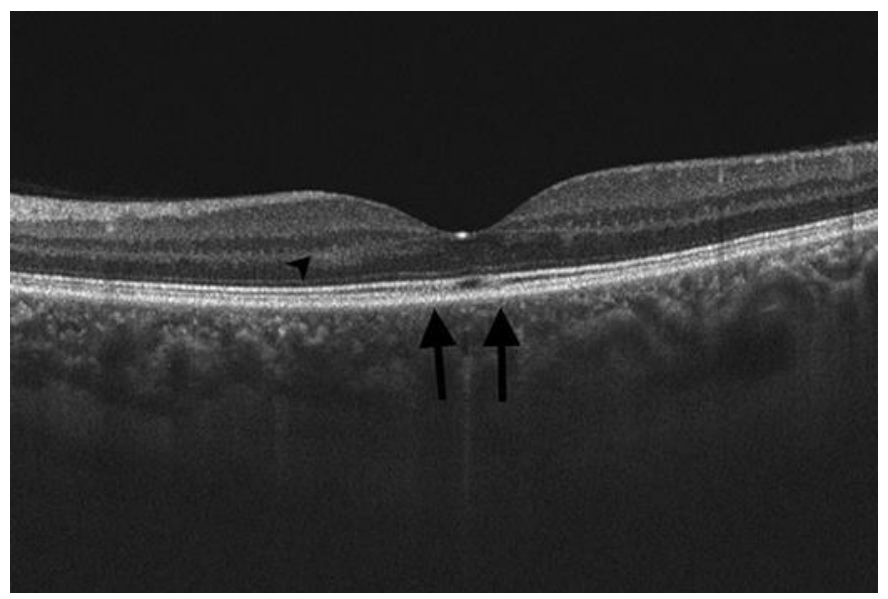

Fig. 1. Optical coherence tomography of the macula of the left injured eye. The arrows are pointing at parafoveolar sites of the disrupted outer plexiform and outer nuclear layer, ellipsoid and interdigitation zone. 
Case Reports in Ophthalmology
Case Rep Ophthalmol 2020;11:395-401 DOI: $10.1159 / 000509264$

(c) 2020 The Author(s). Published by S. Karger AG, Basel www.karger.com/cop

Drača et al.: Enlarged Foveal Avascular Zone after Whiplash Injury-Acquired Berlin's Edema

Left eye (OS) / 15.01.2019 / 16:52:34 Greyscale (CO)
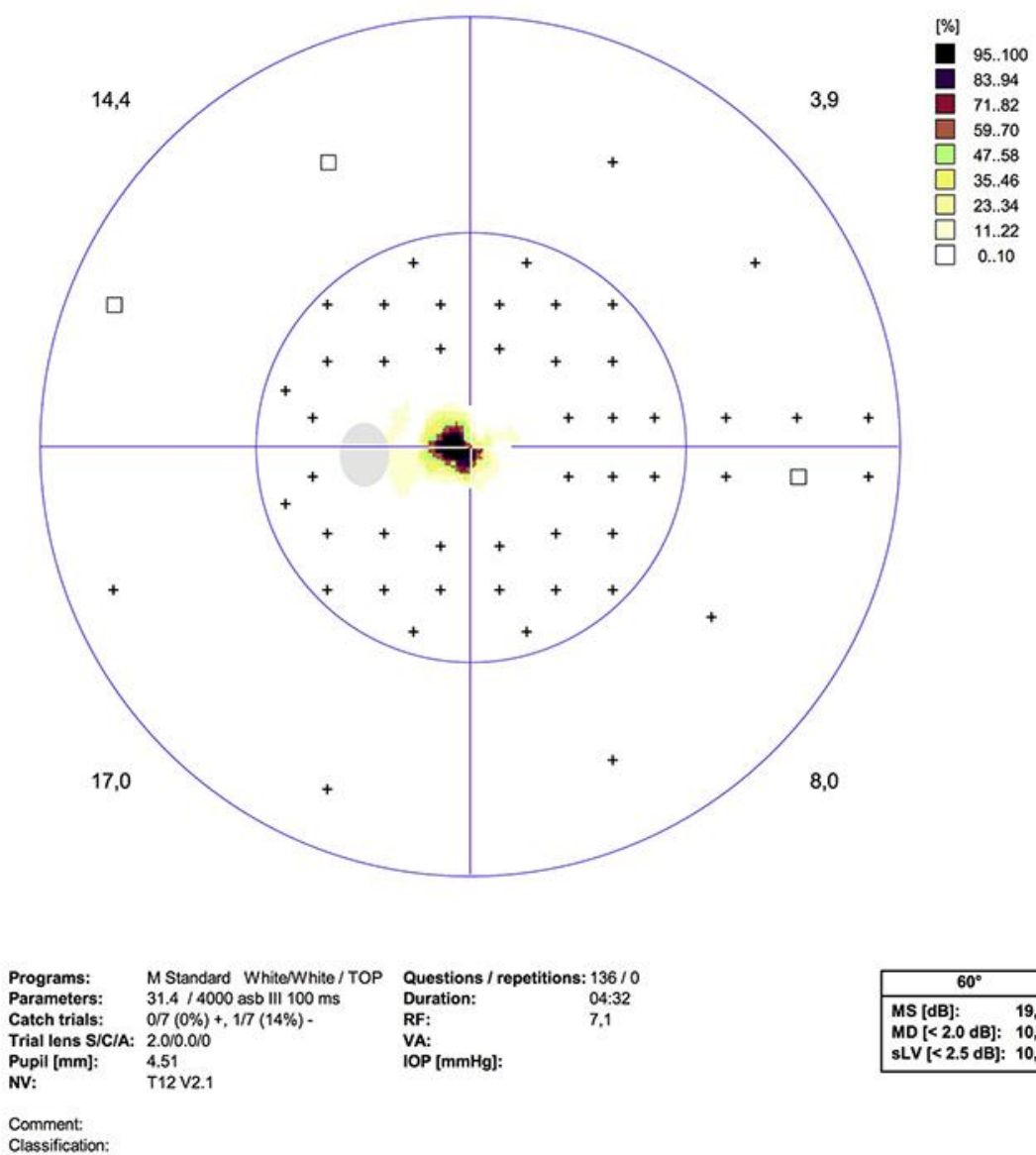

Comment:

Classification:

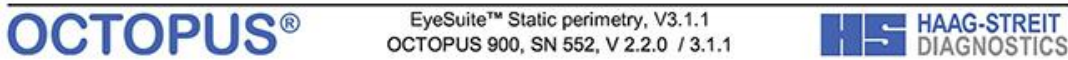

Fig. 2. Visual field in macular (M) standard program (Octopus 900) showed central scotoma of the left eye. 

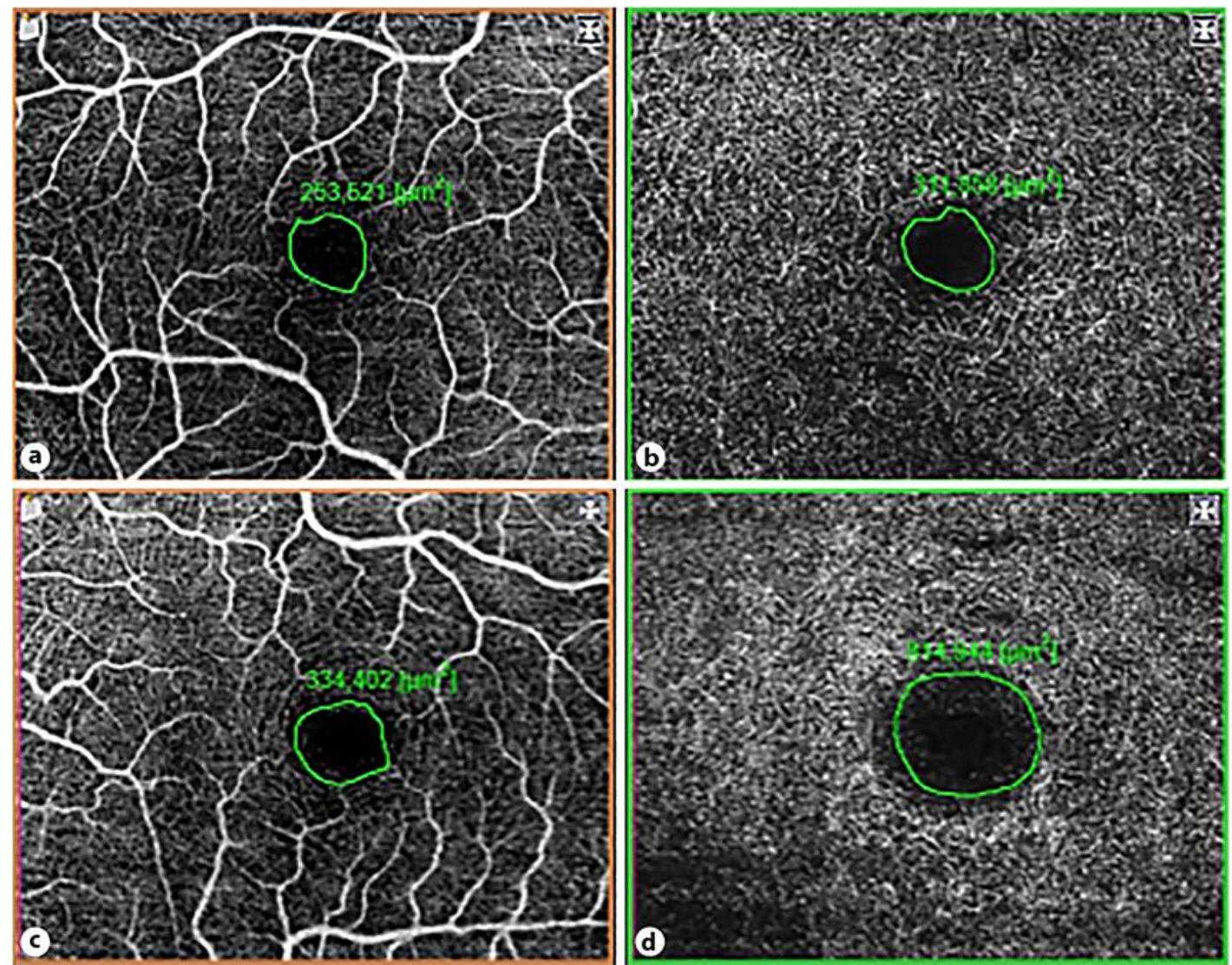

Fig. 3. Optical coherence tomography angiography showed enlarged foveal avascular zone (FAZ) area in the superficial capillary layer (SCL) and deep capillary layer (DCL) in the left eye (LE) as compared to the healthy right eye (RE). a FAZ in SCL of the RE of 253,521 $\mu^{2}$. b FAZ in DCL of the RE of 311,858 $\mu \mathrm{m}^{2}$. c FAZ in SCL of the LE of 334,402 $\mu \mathrm{m}^{2}$. d FAZ in DCL of the LE of $814,944 \mu \mathrm{m}^{2}$. 